\title{
Phase and structural changes during heat treatment of additive manufactured $\mathrm{CrFeCoNi}$ high-entropy alloy
}

\author{
Yulia O. Kuzminova ${ }^{a, *}$, Egor A. Kudryavtsev ${ }^{b}$, Jae-Kyung Han ${ }^{c}$, Megumi Kawasaki $^{\text {, }}$ \\ Stanislav A. Evlashin ${ }^{a}$ \\ a Center for Design, Manufacturing \& Materials, Skolkovo Institute of Science and Technology, Moscow 121205, Russia \\ b The Joint Research Center of Belgorod State National Research University «Technology and Materials», Belgorod 308015, Russia \\ ' School of Mechanical, Industrial \& Manufacturing Engineering, Oregon State University, Corvallis, OR 97331, USA
}

\section{A R T I C L E I N F O}

Article history:

Received 12 June 2021

Received in revised form 4 August 2021

Accepted 6 August 2021

Available online 8 August 2021

\section{Keywords:}

A: high-entropy alloy

$\mathrm{B}$ : additive manufacturing, heat treatment

C: structural evolution, phase composition

\begin{abstract}
A B S T R A C T
Additive manufacturing (AM) of high-entropy alloys (HEAs) is a new challenge in the Material Science and Advanced Manufacturing fields. In the AM processing procedure, heat treatments after fabrication are often beneficial to stabilize microstructure and properties, while limited reports are available for AM HEAs. In the current study, the effect of a post-printing heat treatment at $400-1000{ }^{\circ} \mathrm{C}$ for $24 \mathrm{~h}$ and for 21 days on the changes in structures and phase compositions of an $\mathrm{AM} \mathrm{CrFeCoNi}$ alloy prepared by the laser powder bed fusion AM technique is presented to better understand a heat treatment-microstructure-property relationship of the AM HEA. Heating up to $600{ }^{\circ} \mathrm{C}$ demonstrated the polygonization process in the alloy. Grain growth was observed in the alloy upon heating over $700^{\circ} \mathrm{C}$, while a preferred texture is observed along the build direction after annealing at $900^{\circ} \mathrm{C}$ for $24 \mathrm{~h}$. The formation of the secondary phase was revealed, and it is associated with the impurities of the initial CrFeCoNi powder. The AM CrFeCoNi system demonstrates excellent phase stability inthe solid solution for all annealing temperatures.
\end{abstract}

(c) 2021 Elsevier B.V. All rights reserved.

\section{Introduction}

High-entropy alloys (HEAs) have received great attention in materials science due to their new alloy-design approach in comparison with the conventional alloy developments. Earlier terminology of HEA was used for expressing a single solid solution [1,2]. However, Miracle and Senkov reviewed that the essential group of HEAs contains at least two phases [3]. The presence of secondary phases provides a tangible impact on the mechanical and physical properties of HEAs. For example, a B2/body-centered cubic (bcc) phase formed by the presence of $\mathrm{Al}$ increases the strength characteristics [4-6] as well as the thermal and electrical properties [7] in AlCoCrFeNi alloys. Moreover, precipitations of the $\sigma$-phase nucleated at elevated temperatures of $600-800{ }^{\circ} \mathrm{C}$ increase strength in $\mathrm{Al}_{0.5} \mathrm{CoCrFeMnNi}$ and CoCrFeMnNi alloys [8,9]. A detailed investigation in the phase stability of a CoCrFeMnNi alloy demonstrated the formation of a $\mathrm{Cr}$-rich bcc phase, Fe-Co phase, and $\mathrm{Ni}-\mathrm{Mn}$ $\mathrm{L} 1_{0}$ structure at a temperature range of $500-600{ }^{\circ} \mathrm{C}$ [9-11]. A stable

* Correspondence to: Skolkovo Institute of Science and Technology, Bolshoy Boulevard 30, bld. 1, Moscow 121205, Russia.

E-mail address: yulia.kuzminova@skoltech.ru (Y.O. Kuzminova). face-centered cubic (fcc) solid solution of a CoCrFeMnNi alloy is observed only at temperatures higher than $800{ }^{\circ} \mathrm{C}$ [11], while an ultrafine-grained $\mathrm{CoCrFeNi}$ alloy without Mn provides a stable solid solution after heating up to $\sim 730{ }^{\circ} \mathrm{C}$ [12]. By contrast, Sathiyamoorthi et al. observed the evolution of $\mathrm{Cr}_{7} \mathrm{C}_{3}$ particles in a CoCrFeNi alloy at $600{ }^{\circ} \mathrm{C}$ up to $1000{ }^{\circ} \mathrm{C}[13]$ and the observed phase was expected as the $\sigma$-phase [14].

HEAs are actively constructed through the application of the modern manufacturing techniques such as Additive Manufacturing (AM) $[15,16]$. For the AM process, post-printing heat treatment of the as-built materials is often applied to remove residual stresses, but it leads to structural changes including recrystallization and secondary phase formations [17-19]. Synthesis of CoCrFeMnNi alloys is common by the AM process due to their nature with a ductile fcc structure as matrix, which provides stable printability [19-21]. A $\mathrm{CrFeCoNi}$ alloy also demonstrates the same or even better properties than the five-component alloy [22-25]. The four-component system is actively explored for composition modification by the AM process $[26,27]$. However, the results obtained from structural and phase analyses are contradictory for the quaternary $\mathrm{CoCrFeNi}$ alloy, while the microstructural and phase thermal stabilities are well investigated for the CoCrFeMnNi alloys. Therefore, a comprehensive understanding of the influence of temperature in the post-printing 
Table 1

The chemical composition of $\mathrm{CrFeCoNi}$ powder in wt\%.

\begin{tabular}{lllllll}
\hline $\mathrm{Cr}$ & $\mathrm{Fe}$ & $\mathrm{Co}$ & $\mathrm{Ni}$ & $\mathrm{O}$ & $\mathrm{N}$ & $\mathrm{C}$ \\
\hline 24.65 & 25.09 & 25.47 & 24.55 & 0.129 & 0.095 & 0.015 \\
\hline
\end{tabular}

heat treatment on CoCrFeNi alloy is required for the development of the desirable HEAs having stable structure produced by the current AM techniques.

Accordingly, the present research demonstrates a comprehensive study of structural evolution during post-printing heat treatment of an $\mathrm{AM} \mathrm{CrFeCoNi}$ alloy over a wide temperature range of $400-1000{ }^{\circ} \mathrm{C}$.

\section{Material and methods}

\subsection{Material}

The CrFeCoNi powder (JSC Polema, Russia) with purity of $>$ $99.7 \mathrm{wt} \%$ obtained through a spraying technique was used in the study. Table 1 summarizes the full chemical composition of the powder. Fig. 1 presents (a) the low and (b) high magnifications of the powder morphology. According to previous powder analysis, the particle size distribution poses in a range of 10-60 $\mu \mathrm{m}$ with average size of $27 \mu \mathrm{m}$ [23]. The particles were predominantly spherical, while some particles had irregular shapes.

\subsection{Printing process}

The CrFeCoNi alloy was performed using the widely used laser powder bed fusion (L-PBF) additive manufacturing technique. TruPrint 1000 metal 3D printer (TRUMPF) was used in the current work to manufacture the samples with the selected printing process parameters according to the results from the previous study [18]. A full list of the applied parameters is shown in Table 2. The samples were printed with the chess $X-Y$ scan strategy with a square side of $4 \mathrm{~mm}$ (detailed information of the applied scan strategy is described
Table 2

A list of the applied printing process parameters.

\begin{tabular}{ll}
\hline L-PBF parameter & Values \\
\hline Laser power & $150 \mathrm{~W}$ \\
Laser spot diameter & $55 \mu \mathrm{m}$ \\
Hatch spacing & $80 \mu \mathrm{m}$ \\
Layer thickness & $20 \mu \mathrm{m}$ \\
Laser scan speed & $600 \mathrm{~mm} / \mathrm{s}$ \\
Gas speed (Ar) & $2.5 \mathrm{~m} / \mathrm{s}$ \\
Oxygen level & $<0.3 \mathrm{at} \%$ \\
Pressure in chamber & $1 \mathrm{bar}$ \\
\hline
\end{tabular}

elsewhere [28]). Totally, 10 cylindrical samples were printed with a diameter and a height of $10.0 \mathrm{~mm}$ and $10.0 \mathrm{~mm}$, respectively. The printing process was conducted without platform preheating.

\subsection{Heat treatment process}

The printed samples were annealed at different temperatures in the range of $400-1000^{\circ} \mathrm{C}$ with a step of $100^{\circ} \mathrm{C}$ in air. The cylindrical samples were disposed of in the furnace SNOL 6.7-1300 (AB UMEGA GROUP) preheated to the required temperature. Each sample was annealed for $24 \mathrm{~h}$ with the following cooling in water. Additionally, the long heat treatment in air was applied to the as-built samples at temperatures of 600 and $700^{\circ} \mathrm{C}$ for 21 days.

\subsection{Differential scanning calorimetry}

Thermal stability of the CrFeCoNi powder and the as-built CrFeCoNi sample was studied using differential scanning calorimetry (DSC) analysis using the thermal analyzer STA 449 F3 Jupiter (NETZSCH) with a heating speed of $20 \mathrm{~K} / \mathrm{min}$ up to $900{ }^{\circ} \mathrm{C}$ in $\mathrm{Ar}$ atmosphere.

\subsection{Microhardness testing}

Top sample surfaces were prepared for the microhardness tests with the 2000-grit SiC papers. A Vickers microhardness testing

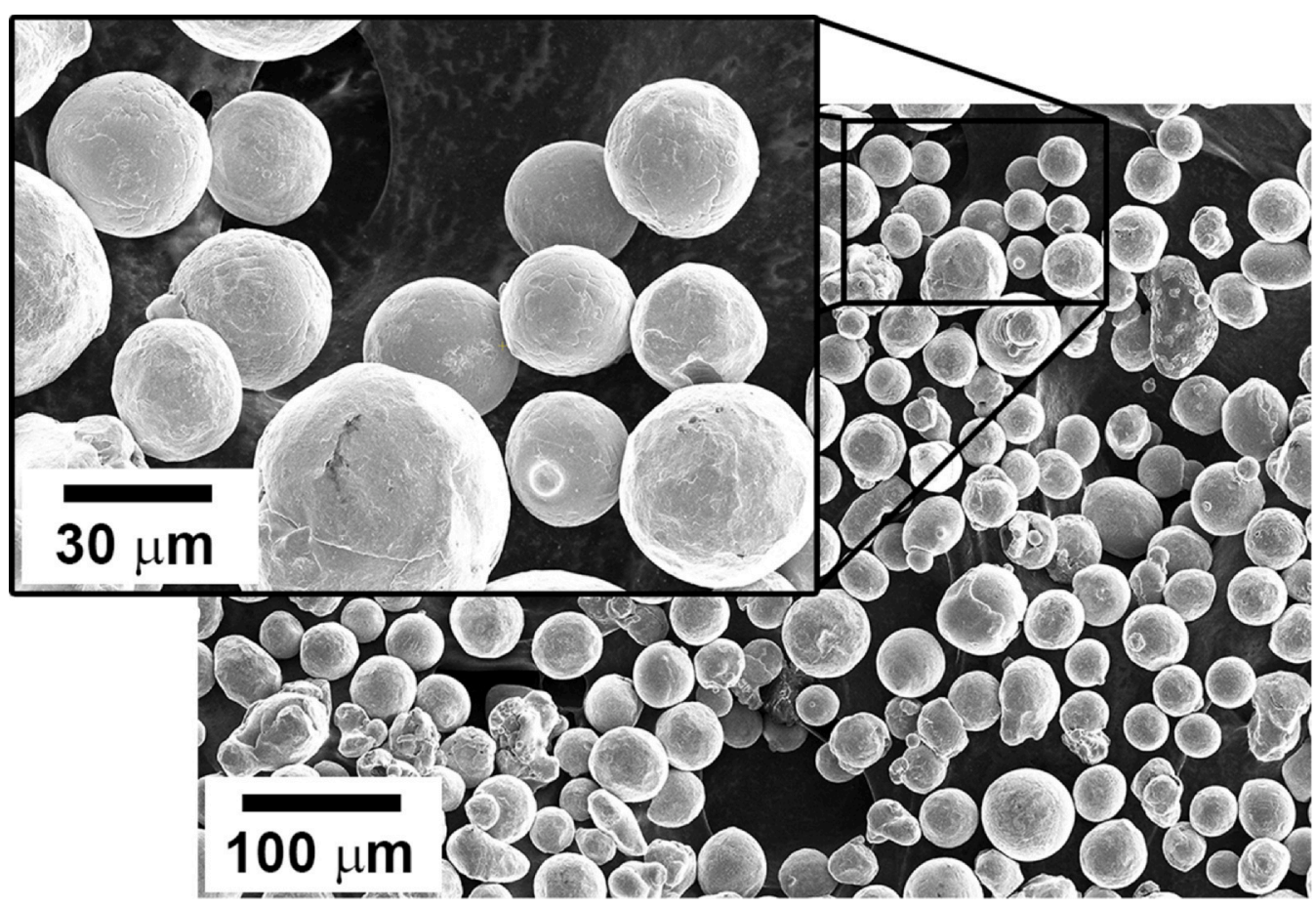

Fig. 1. SEM images of the $\mathrm{CrFeCoNi}$ powder at low and high magnifications. 
machine ITV-1-AM (Metrotest, Russia) was used for the microhardness tests under a load of $300 \mathrm{~g}$ for at least 10 measurements per sample.

\subsection{Structural and phase analyses}

Structural analysis was performed using a scanning electron microscope Quattro S (Thermo Fisher Scientific Inc., USA) equipped with an energy dispersive X-ray (EDX) detector. The samples were cut perpendicularly to the build direction, ground using the $\mathrm{SiC}$ grinding papers up to 2000-grit, and polished with a diamond suspension (up to $3 \mu \mathrm{m}$ ) and silica oxide suspension (up to $40 \mathrm{~nm}$ ). A transmission electron microscope (TEM) JEM-2100 (JEOL, Japan) was used for the microstructural and phase analyses with the accelerating voltage of $200 \mathrm{kV}$. The samples were prepared by cutting transversely to the build direction and thinned up to $100 \mu \mathrm{m}$ using the $\mathrm{SiC}$ grinding papers. The mixture of $95 \% \mathrm{CH}_{3} \mathrm{COOH}$ and $5 \% \mathrm{HClO}_{4}$ at the $25 \mathrm{~V}$ potential was applied for the twin-jet electropolishing using TenuPol5 machine (Struers, Denmark). To minimize the edge effect, all structural investigations were made in the sample centers. The analysis of light elements was performed using determinators LECO TC-136 and LECO SC-144 (LECO Corporation, USA). The structural calculations from images were made using the open source software ImageJ developed by National Institute of Health (USA).

Bruker D8 ADVANCE (Bruker, USA) diffractometer with CoK $\alpha$ radiation (wavelength $=1.79026 \AA$ ) was applied for performing the $\mathrm{X}$-ray diffraction (XRD) analysis. The top surfaces of the samples was polished with the 2000-grit SiC grinding paper, polished with the final silica oxide suspension of $40 \mathrm{~nm}$, and electropolished with LectroPol-5 (Struers, Denmark) using a solution of $900 \mathrm{ml}$ $\mathrm{C}_{4} \mathrm{H}_{9} \mathrm{OH}+100 \mathrm{ml} \mathrm{HClO}_{4}$ at the $\sim 28 \mathrm{~V}$ potential. The XRD patterns were obtained in the $2 \theta$ range from $47^{\circ}-125^{\circ}$ with a step size of $0.07^{\circ}$ and an incremental time of $2.0 \mathrm{~s}$.

\section{Results}

\subsection{Thermal analysis and hardness evolution of CrFeCoNi alloy}

Fig. 2 presents the DSC traces from $200^{\circ} \mathrm{C}$ to $900{ }^{\circ} \mathrm{C}$ for the powder and the bulk as-built samples of the CrFeCoNi alloy. The curve for the as-built sample has two endothermic peaks at $\sim 500^{\circ} \mathrm{C}$ and $\sim 610^{\circ} \mathrm{C}$ overlapping each other. The first peak begins at $400^{\circ} \mathrm{C}$ with a peak at $500^{\circ} \mathrm{C}$, and it switches to the next peak with the

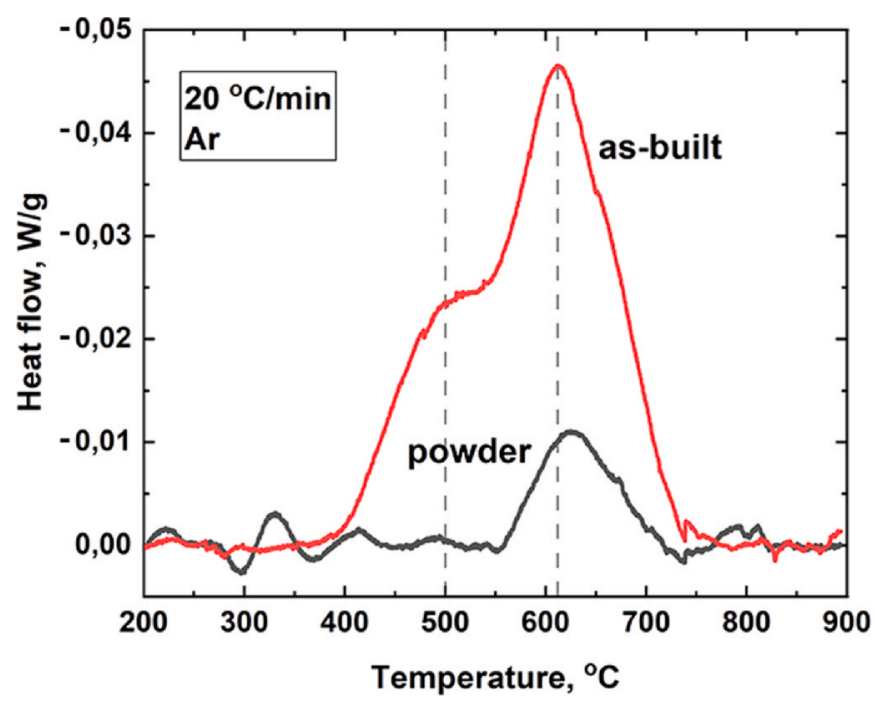

Fig. 2. DSC thermograms obtained for the powder and as-built sample of AM $\mathrm{CrFeCoNi}$ at heating rate $20^{\circ} \mathrm{C} / \mathrm{min}$ in an argon atmosphere. a)

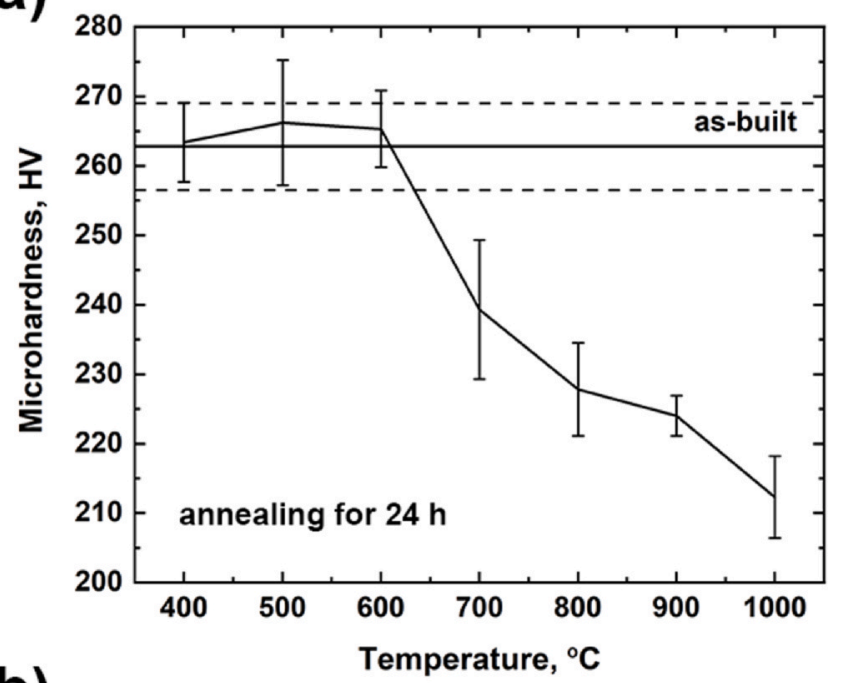

b)

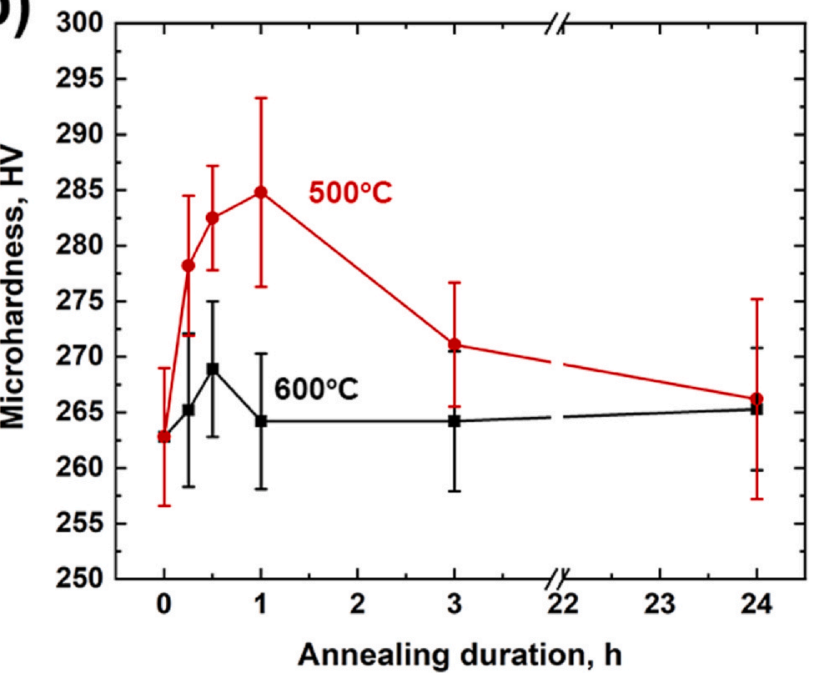

Fig. 3. Effect of (a) temperature and (b) duration of annealings at 500 and $600{ }^{\circ} \mathrm{C}$ on microhardness of AM CrFeMnNi alloy. The microhardness of as-built $\mathrm{CrFeMnNi}$ alloy in Fig. 3a is presented as the horizontal line and its standard deviation error as dotted lines.

highest at $610^{\circ} \mathrm{C}$ and a finish at $740{ }^{\circ} \mathrm{C}$. The powder sample shows only one peak starting at $550{ }^{\circ} \mathrm{C}$ and a finish at $740{ }^{\circ} \mathrm{C}$, where the single peak seems consistent with the second peak of the as-built sample but with less intensity.

The connected first and second peaks of the exothermic peaks may be attributed to the recovery and recrystallization of the asbuilt $\mathrm{CrFeCoNi}$ alloy. Specifically, the first peak is related to the recovery process. The second peak for the as-built sample and the only distinguishable peak for the powder are associated with the recrystallization process. The highly strained as-built sample may provide the thermal peak shifting to lower temperatures in comparison to the powder sample. It is worth noting that an ultrafinegrained conventionally-manufactured $\mathrm{CrFeCoNi}$ alloy demonstrated the exothermic DSC peaks at $407^{\circ} \mathrm{C}$ and $597^{\circ} \mathrm{C}$ [12]. Considering the highly strained ultrafine-grained condition leading to the lower DSC peaks, the present as-built $\mathrm{CrFeCoNi}$ alloy demonstrated reasonable thermal characteristics. The integration of the thermal peak area yields $4.8 \mathrm{~J} / \mathrm{g}$ for the powder and $6.8 \mathrm{~J} / \mathrm{g}$ and $22.5 \mathrm{~J} / \mathrm{g}$ for the first and the second peaks, respectively, for the as-built sample according to Gaussian peaks fitting.

Fig. 3 shows the effect of (a) annealing temperature for $24 \mathrm{~h}$ of heating and (b) duration of annealings at 500 and $600{ }^{\circ} \mathrm{C}$ for $24 \mathrm{~h}$ on 

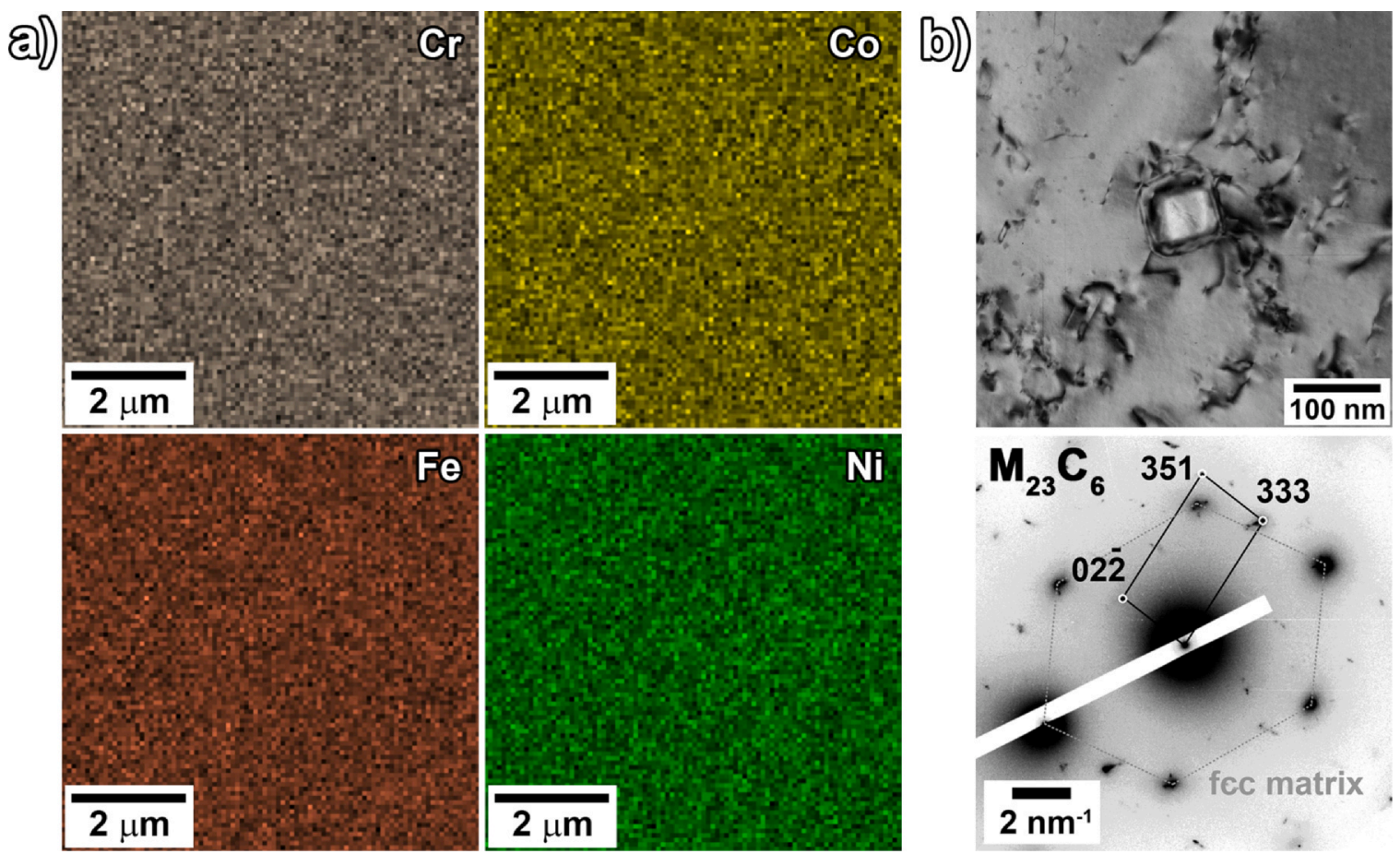

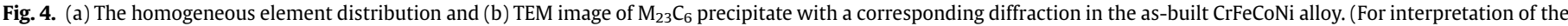
references to color in this figure legend, the reader is referred to the web version of this article.)

microhardness of the AM CrFeCoNi alloy. Hardness of the as-built sample before annealing is $\sim 263 \mathrm{HV}$ that is denoted with a solid horizontal line with the error values with the dotted-lines in Fig. $3 \mathrm{a}$. After annealing at $400^{\circ} \mathrm{C}$, the hardness is similar compared with the as-built sample, and it reaches $267 \mathrm{HV}$ at $500-600^{\circ} \mathrm{C}$ which is higher than the as-built condition. Thereafter, hardness showed a continuous drop towards $\sim 212 \mathrm{HV}$ with increasing annealing temperature to $1000^{\circ} \mathrm{C}$. The short annealing at $500^{\circ} \mathrm{C}$ increases the material hardness which achieves the highest value of $\sim 285 \mathrm{HV}$ after $1 \mathrm{~h}$ and further decreases toward $267 \mathrm{HV}$ after $24 \mathrm{~h}$, Fig. 3b. The hardness measurements during annealing at $600{ }^{\circ} \mathrm{C}$ demonstrate the highest microhardness value after $30 \mathrm{~min}$ and a slight decrease after $1 \mathrm{~h}$, which is then maintained consistent up to $24 \mathrm{~h}$ of annealing.

\subsection{Microstructural evolution upon the annealing}

Fig. 4 represents (a) the homogeneous element distributions taken by EDX analysis with no proof of secondary phase in the asbuilt $\mathrm{CrFeCoNi}$ alloy, while (b) the TEM image with corresponding TEM diffraction is indicating a presence of nano-scale $\mathrm{M}_{23} \mathrm{C}_{6}$ precipitates [29] in the material. Fig. 5 consists of the backscattered electron (BSE) images transversally to the build direction (BD) with two different magnifications of $(\mathrm{a}, \mathrm{b})$ the as-built $\mathrm{CrFeCoNi}$ alloy before annealing and after annealing at (c, d) $400{ }^{\circ} \mathrm{C}$ and (e, f) $500{ }^{\circ} \mathrm{C}$ for $24 \mathrm{~h}$, and the TEM images of the $\mathrm{CrFeCoNi}$ alloy in ( $\mathrm{g}$ ) an as-built condition and (h) after annealing at $400^{\circ} \mathrm{C}$. The as-built sample demonstrates the bimodal grain size distributions (Fig. 5a) where there are coarse grains with lengths of $\sim 50 \mu \mathrm{m}$ and widths of $\sim 8 \mu \mathrm{m}$ elongated transversally to the moving of the melt pool and a finegrained structure between the neighboring melt tracks. The domains in the fine structure consist of subgrains (Fig. 5b) where a cellular substructure consists of elongated subgrains having a width of $\sim 450 \mathrm{~nm}$ and a length of $\sim 700 \mathrm{~nm}$ (Fig. $5 \mathrm{~g}$ ). Such cellular structure is responsible for higher strength characteristics in AM materials [30-32]. Note that the subgrains form a columnar structure following the build direction, where the elongation indicates their growth oblique to the build direction [33]. The microstructure remained reasonably consistent after annealing at $400{ }^{\circ} \mathrm{C}$ (Fig. 5c) where both elongated and fine grains are still visible and the consistent substructure with average size of $\sim 480 \mathrm{~nm}$ is observed with the formation of dislocation walls (Fig. $5 \mathrm{~d}$ and $\mathrm{h}$ ). After annealing at $500{ }^{\circ} \mathrm{C}$ for $24 \mathrm{~h}$, the square domains with sizes of $\sim 35 \mu \mathrm{m}$ appear and the elongated structure appears to be ambiguous (Fig. 5e), while the cell substructure after annealing at $500^{\circ} \mathrm{C}$ remains consistent with the materials in as-built and as-annealed at $400^{\circ} \mathrm{C}$ (Fig. 5 f).

Fig. 6 shows the microscopic images of the $\mathrm{AM} \mathrm{CrFeCoNi}$ alloy after annealing at (a, b) $600^{\circ} \mathrm{C},(\mathrm{c}, \mathrm{d}, \mathrm{e}) 700^{\circ} \mathrm{C}$, and (f) $800^{\circ} \mathrm{C}$ for $24 \mathrm{~h}$. Annealing at $600^{\circ} \mathrm{C}$ leads to the polygonization process. In practice, the polygonized domains with smooth borders appear next to the fine structure (Fig. 6a), while the cellular substructure with cells of $\sim 450 \mathrm{~nm}$ is formed within the domains (Fig. 6b). Note, the size of such domains having the length of $\sim 55 \mu \mathrm{m}$ and thickness of $\sim 7 \mu \mathrm{m}$ is similar to as-built structure. An increase in the annealing temperature towards $700^{\circ} \mathrm{C}$ shows recrystallized grains in the entire fine grain regions with average size of $\sim 1.5 \mu \mathrm{m}$, while the melt track with the elongated grains is inherited in some local regions (Fig. 6c). In higher magnification, secondary phase precipitates are observed at grain borders and these are denoted by white arrows (Fig. 6d). The TEM image presents a degradation of cellular structure and dislocation-free grains in the regions where recrystallization occurs (Fig. 6e). The dislocation walls of the substructure are degraded, and, instead, the dislocations migrate to grain borders and some subgrains coalesce. The BSE image of the AM CrFeCoNi alloy annealed at $800^{\circ} \mathrm{C}$ reveals the further developed recrystallization process and the impedance of the grain borders coalescence by the secondary phase precipitates that are marked by white arrows (Fig. 6f). After $800^{\circ} \mathrm{C}$ annealing, the grain size of the substructure is in the range of $0.5-3.3 \mu \mathrm{m}$. It should be mentioned that due to high irregularity of the microstructure after annealing at 700 and $800{ }^{\circ} \mathrm{C}$, the estimation of the precise grain sizes is complicated.

Fig. 7 presents the BSE images of the AM CrFeCoNi alloy followed by annealing for $24 \mathrm{~h}$ at (a) $900^{\circ} \mathrm{C}$ and (b, c) $1000^{\circ} \mathrm{C}$, and (d) a TEM 

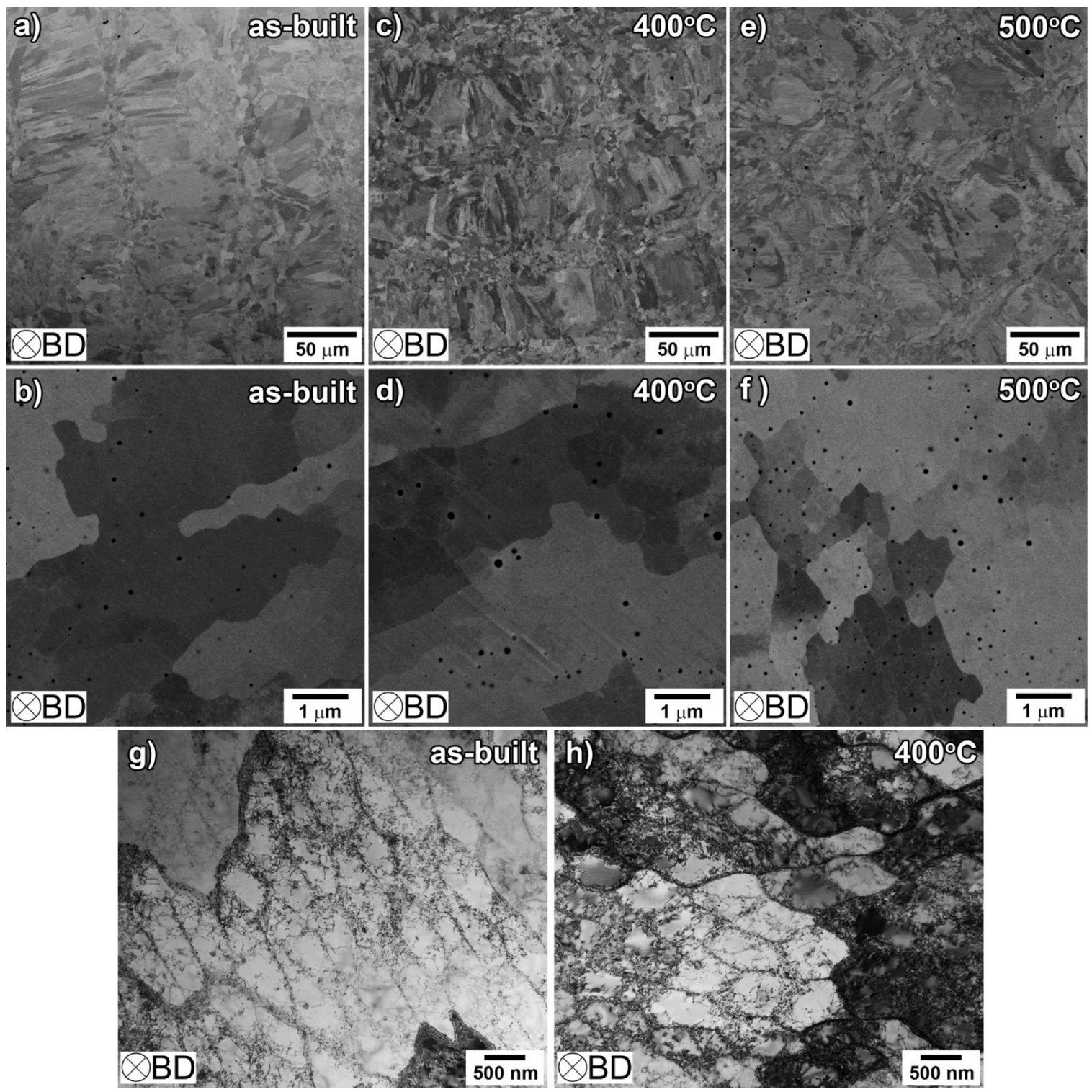

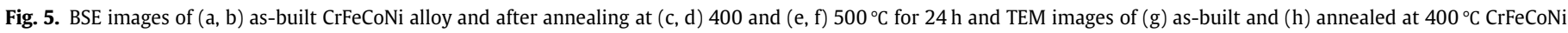
alloy.

image of the as-annealed alloy at $900{ }^{\circ} \mathrm{C}$. After annealing at $900{ }^{\circ} \mathrm{C}$, newly formed large grains with size of $5-10 \mu \mathrm{m}$ are visible in the formally fine-grained region (Fig. 7a). As seen in the depicted image in Fig. 7a, the formation of recrystallized small grains also occurs (marked by white arrows). The domain walls are formed by the dissolved subgrain borders consisting of dislocations, which are visible in the TEM micrographs where the dissolved subgrain borders promote dislocation pile-ups and intragranular dislocations are visible in the observed region of the alloy after annealing at $900{ }^{\circ} \mathrm{C}$ (Fig. 7d). After $900^{\circ} \mathrm{C}$ annealing, the average size of microstructure is $\sim 1260 \mathrm{~nm}$. The bimodal microstructure is still observed after annealing at $1000^{\circ} \mathrm{C}$ in the $\mathrm{AM} \mathrm{CrFeCoNi}$ alloy (Fig. 7b), while the high magnification micrograph shows a replacement of the fine structure to the equiaxed recrystallized grains with sizes of $\sim 0.5-2.5 \mu \mathrm{m}$ (Fig. 7c).

In previous works, the precipitates observed in a $\mathrm{CrFeCoNi} \mathrm{mi-}$ crostructure after annealing at $750{ }^{\circ} \mathrm{C}$ and $800^{\circ} \mathrm{C}$ are considered as the $\sigma$-phase $[18,23]$. In order to examine detailed structure of the secondary phase in the alloy heated at different temperatures and treatment time, TEM diffraction analysis was performed for the alloy after annealing for $24 \mathrm{~h}$. Fig. 8 shows TEM diffractions for the precipitates observed in the AM CrFeCoNi alloy after annealing at (a) $700^{\circ} \mathrm{C}$ and (b) $900^{\circ} \mathrm{C}$. The analysis reveals that the consistent $\mathrm{M}_{2} \mathrm{~N}$ structure [34] presents in both samples. The presence of the secondary phase is further confirmed by a long-term heat treatment at $700^{\circ} \mathrm{C}$ for 21 days leading to the coarsening of the precipitates in the as-built $\mathrm{CrFeCoNi}$ alloy and it is available by EDX analysis as shown in Fig. 9a. It was determined that the precipitates are rich in $\mathrm{Cr}$ (up to $50 \mathrm{at} \%$ ) with an equal value of other elements and high values of $\mathrm{N}$ and 0 . Table 3 presents the detailed composition of spots presented in Fig. 9a. Moreover, the as-built $\mathrm{CrFeCoNi}$ alloy was also heat treated at $600{ }^{\circ} \mathrm{C}$ for 21 days to evaluate the presence of the secondary phase with the $\mathrm{M}_{2} \mathrm{~N}$ structure during the recrystallization process at $600^{\circ} \mathrm{C}$, and a BSE image of the CrFeCoNi sample is shown in Fig. 9b. The formation of $\mathrm{Cr}$-rich precipitates were visible along grain boundaries after the long heat treatment at $600^{\circ} \mathrm{C}$. Note that the formation of the secondary phase may affect the recrystallization behavior of the as-built $\mathrm{CrFeCoNi}$ alloy. The analysis of $\mathrm{N}$ content was performed using a combustion method due to the low effectiveness of EDX method for the analysis of light elements. As it was presented in 


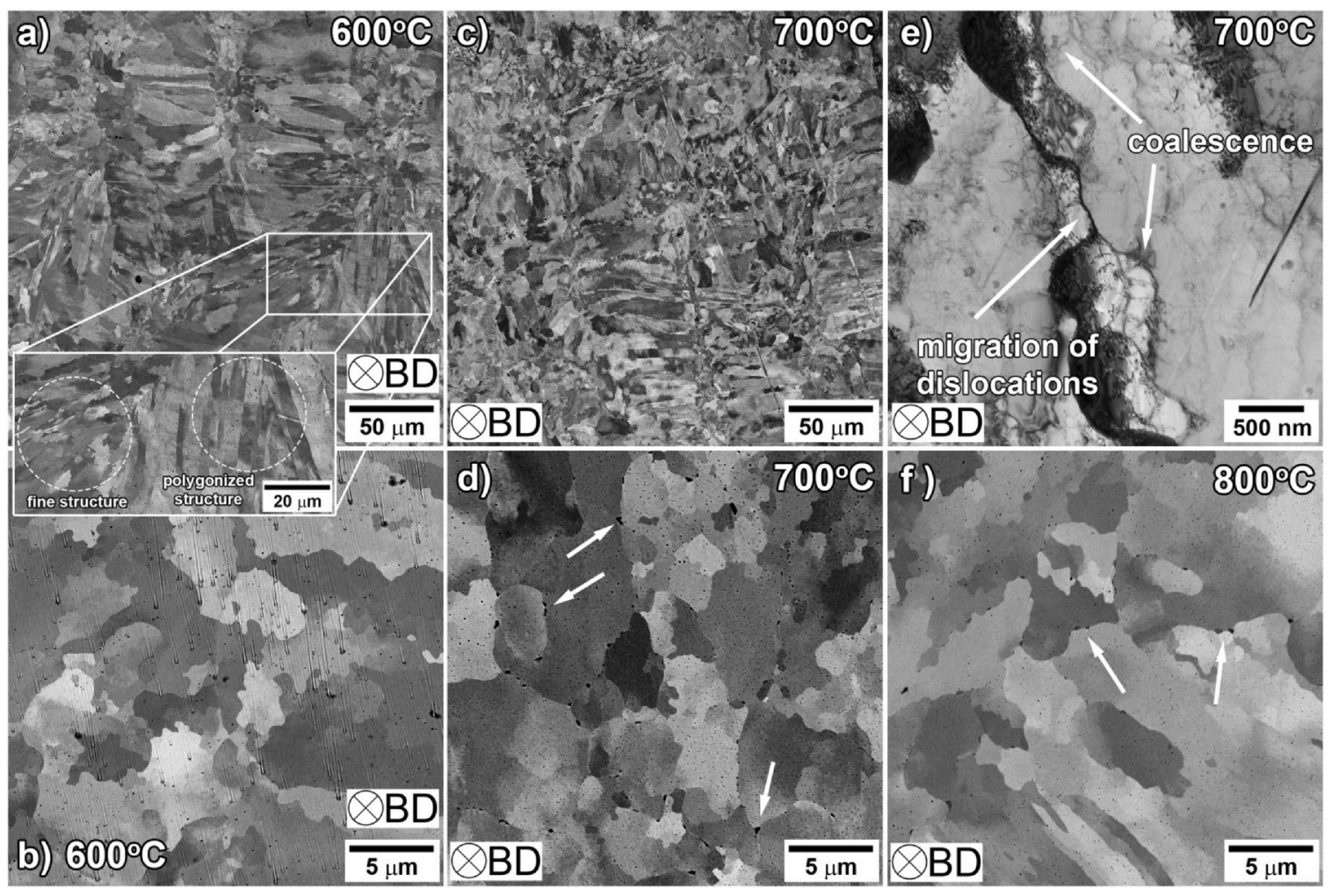

Fig. 6. The images of $\mathrm{CrFeCoNi}$ structures after annealing at temperatures of $(\mathrm{a}, \mathrm{b}) 600^{\circ} \mathrm{C},(\mathrm{c}, \mathrm{d}, \mathrm{e}) 700^{\circ} \mathrm{C}$, and (f) $800^{\circ} \mathrm{C}$. All images are BSE except the $6 e$ which is represented as a TEM micrograph.
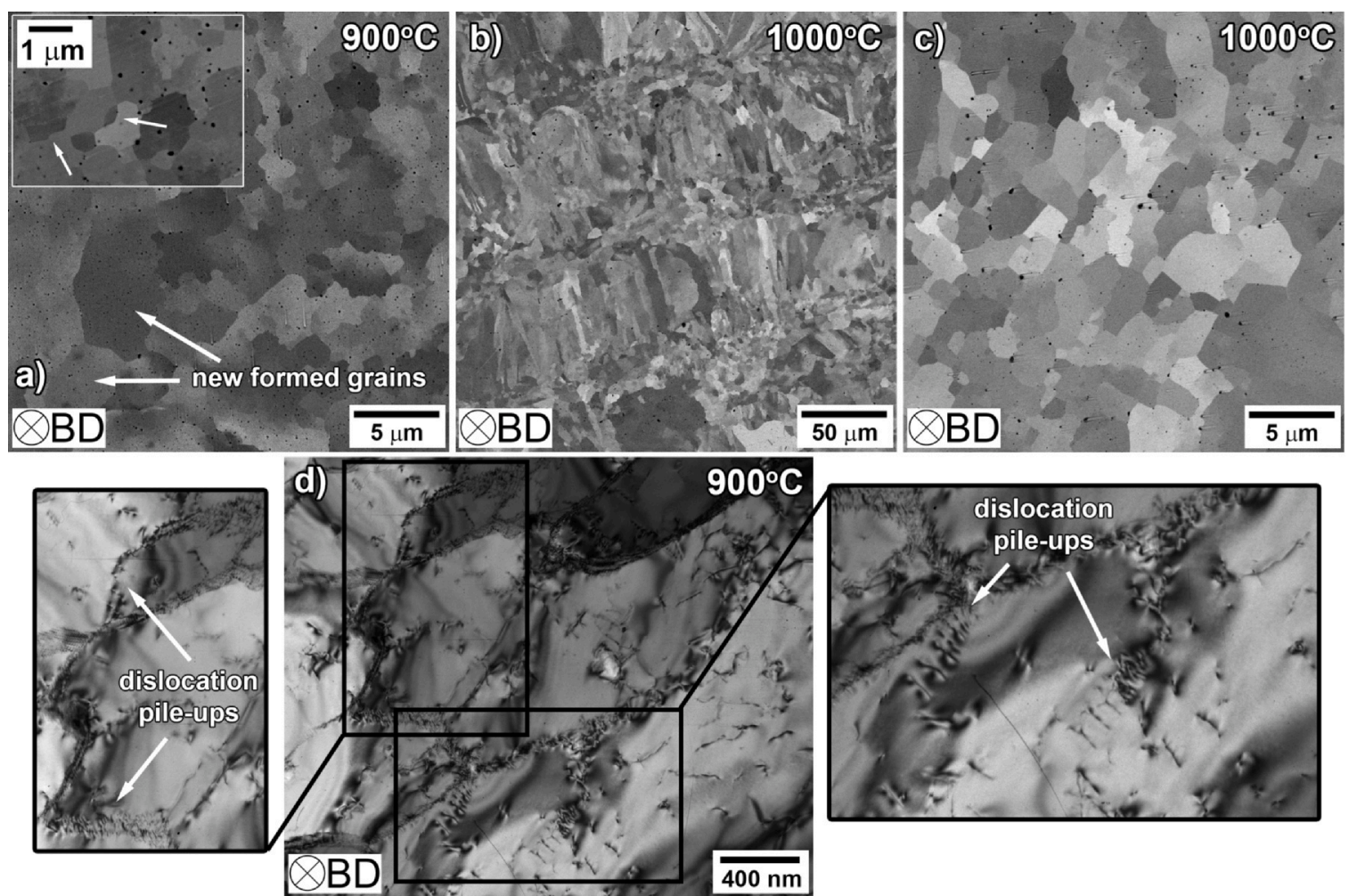

Fig. 7. BSE images of $\mathrm{AM} \mathrm{CrFeCoNi}$ alloy after annealing at (a) 900 and (b, c) $1000^{\circ} \mathrm{C}$ and (d) the TEM image of as-annealed at $900{ }^{\circ} \mathrm{C} \mathrm{CrFeCoNi}$ alloy. 

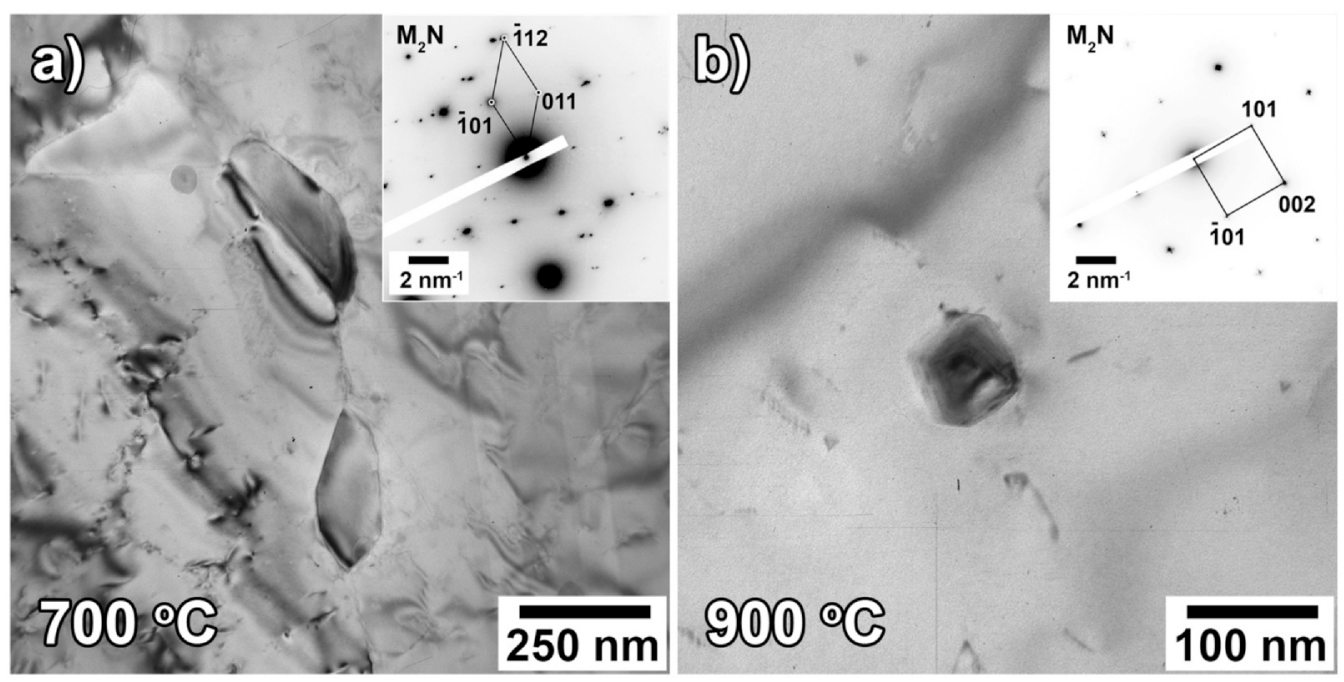

Fig. 8. TEM diffraction of precipitates found at the AM CrFeCoNi after annealing at (a) 700 and (b) $900{ }^{\circ} \mathrm{C}$.
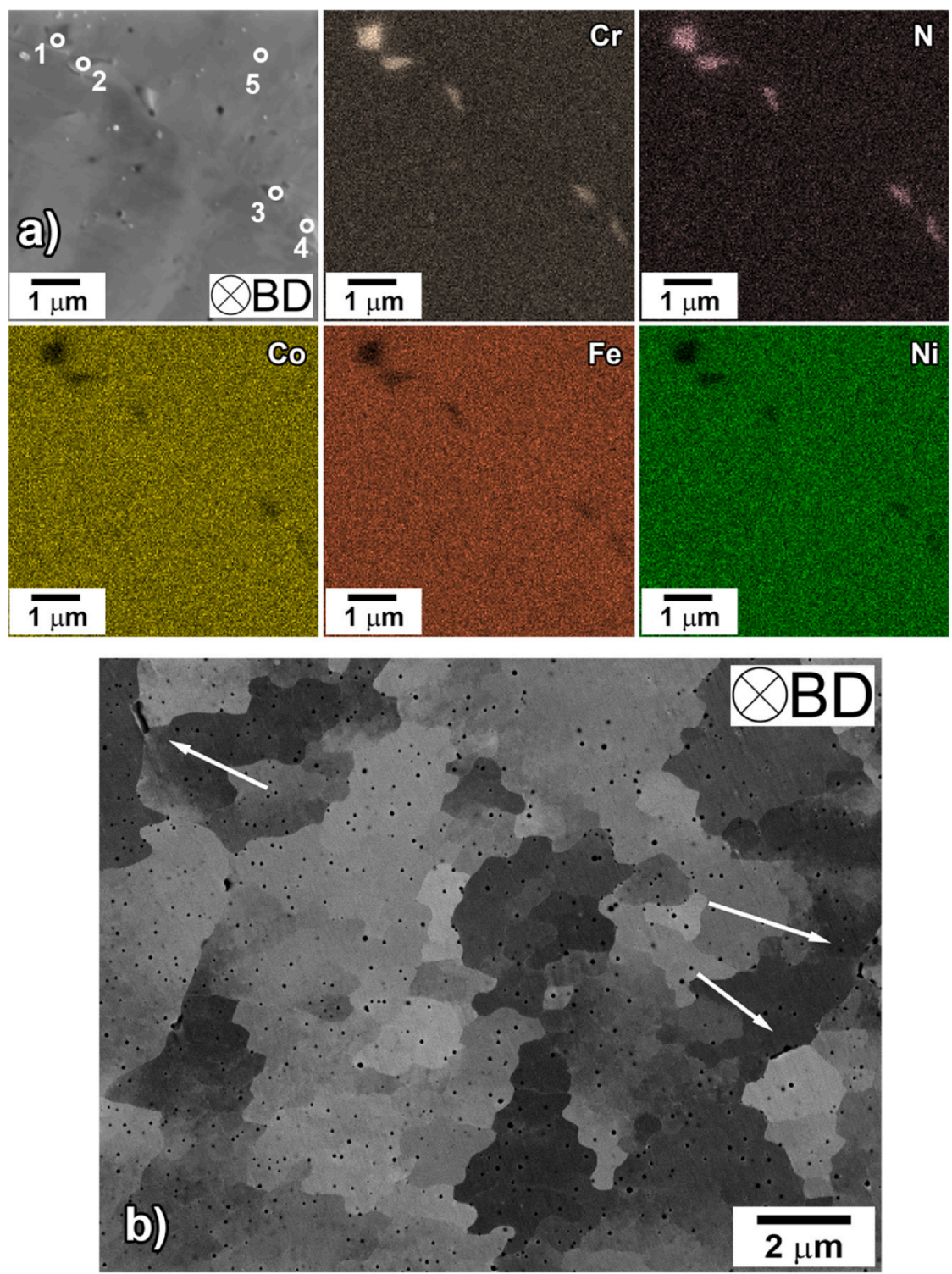

Fig. 9. (a) EDX result of $\mathrm{AM} \mathrm{CrFeCoNi}$ alloy annealed at $700^{\circ} \mathrm{C}$ for 21 days; (b) BSE image of AM CrFeCoNi alloy annealed at $600{ }^{\circ} \mathrm{C}$ for 21 days. (For interpretation of the references to color in this figure legend, the reader is referred to the web version of this article.) 
Table 3

The chemical composition (in wt\%) of $\mathrm{CrFeCoNi}$ alloy annealed at $700{ }^{\circ} \mathrm{C}$ for 21 days estimated with EDX. The number of points corresponds to the locations with the consistent numbers in Fig. 9a.

\begin{tabular}{|c|c|c|c|c|c|c|c|}
\hline & $C$ & 0 & $\mathrm{~N}$ & $\mathrm{Cr}$ & $\mathrm{Fe}$ & Co & $\mathrm{Ni}$ \\
\hline spot 1 & 7.42 & 13.53 & 4.76 & 48.20 & 9.79 & 8.61 & 7.69 \\
\hline spot 2 & 7.60 & 11.94 & 4.28 & 40.10 & 13.08 & 12.07 & 10.93 \\
\hline spot 3 & 6.58 & 10.36 & 4.28 & 33.92 & 16.01 & 15.12 & 13.73 \\
\hline spot 4 & 7.45 & 9.13 & 4.16 & 29.98 & 17.33 & 16.44 & 15.51 \\
\hline spot 5 & 7.32 & 1.22 & 2.89 & 22.73 & 22.77 & 21.99 & 21.08 \\
\hline
\end{tabular}

Table $1,0.095 \mathrm{wt} \%$ of $\mathrm{N}$ in the powder was determined. There is relatively the same content of $\mathrm{N}(\sim 0.085 \mathrm{wt} \%)$ in the printed samples before heat treatment and after annealing at $700{ }^{\circ} \mathrm{C}$ for $24 \mathrm{~h}$ as well as 21 days. After printing, the contents of $\mathrm{O}$ and $\mathrm{C}$ in the material also drop toward $\sim 0.115$ and $\sim 0.004 \mathrm{wt} \%$, respectively, and stay at approximately the same level after the annealing at $700^{\circ} \mathrm{C}$ up to 21 days.

Fig. 10 presents (a) the X-ray profiles of the powder, the as-built $\mathrm{CrFeCoNi}$ alloy before and after annealing at 400,700 , and $900^{\circ} \mathrm{C}$ for $24 \mathrm{~h}$ and the BSE images of $\mathrm{CrFeCoNi}$ alloy at (b) as-printed and (c) as-annealed at $1000^{\circ} \mathrm{C}$ for $24 \mathrm{~h}$ conditions. According to XRD analysis, all samples present a pure fcc structure, Fig. 10a. The dotted lines indicate the interplanar distance for corresponding planes for the crystal structure with a lattice parameter of $3.58 \AA$. In contrast to compositional analysis, no additional phases such as $\mathrm{M}_{23} \mathrm{C}_{6}$ precipitates and $\mathrm{Cr}$-rich precipitates with $\mathrm{M}_{2} \mathrm{~N}$ structure were determined both before and after annealing due to their small contents below $\sim 5$ vol\%, which is the XRD detection limit. Only the powder profile reveals the dominant (111) peak, while all other profiles for as-built samples demonstrate the strong texture of $<100>$ and $<$ $110>$ toward the build direction. It is reported for the 3161 stainless steel having an fcc structure the $<110>$ crystal texture alignments with the build direction and the $<100>$ crystal texture with the laser track [33]. In the current study with the CrFeCoNi alloy, the difference in the XRD peak intensity is associated with the texture variety between the $<100>$ and $<110>$ along the printed sample heights, and the tendency is maintained after annealing at $900^{\circ} \mathrm{C}$ for $24 \mathrm{~h}$. As can be seen in Fig. 10b and c, the preferable texture is observed even after $1000^{\circ} \mathrm{C}$ annealing for $24 \mathrm{~h}$.

\section{Discussion}

\subsection{Structural evolution}

DSC analysis demonstrates two endothermic peaks for the asbuilt $\mathrm{CrFeCoNi}$ alloy at 500 and $610^{\circ} \mathrm{C}$. The first peak is associated with the recovery process in the material, which agrees with the results of SEM analysis revealing no structural changes up to $600{ }^{\circ} \mathrm{C}$. The second DSC peak at $610^{\circ} \mathrm{C}$ ending at $740{ }^{\circ} \mathrm{C}$ is associated with the following two processes. The first process is related to the beginning of the recrystallization of the material. At $700^{\circ} \mathrm{C}$, the grains grow and degradation of dislocation walls are observed in the material. The second process is associated with the secondary phase formation, where TEM and EDX analyses demonstrated the appearance of the $\mathrm{Cr}$-rich precipitates with $\mathrm{M}_{2} \mathrm{~N}$ structure at the temperature range of $700-800^{\circ} \mathrm{C}$ after heating for $24 \mathrm{~h}$. It should be noted that the long heat treatment at lower temperature can also form the nitrides in $\mathrm{CrFeCoNi}$ alloy, as shown in Fig. 9b. Thus, the contributions of the recrystallization process and the secondary phase formation process to the second DSC peak can be influenced by the heat treatment conditions. Note, Sathiyamoorthi et al. performing the DSC analysis on mechanically alloyed $\mathrm{CoCrFeNi}$ powder observed the exothermic peak at $600{ }^{\circ} \mathrm{C}$, which was associated with the appearance of $\mathrm{Cr}_{7} \mathrm{C}_{3}$ precipitates [13]. In the present study, the carbides with $\mathrm{M}_{23} \mathrm{C}_{6}$ structure were observed in the as-built condition (Fig. 4b). Shun and Du considered the decomposition of the $\mathrm{Cr}_{7} \mathrm{C}_{6}$ carbide to $\mathrm{Cr}_{23} \mathrm{C}_{6}$ in $\mathrm{Al}_{0.3} \mathrm{CoCrFeNiC}_{0.1}$ alloy at temperatures of $800-1000{ }^{\circ} \mathrm{C}$ [35]. The presence of both carbide types is possible in the current AM CrFeCoNi. However, in contrast to the studies [13,35], the present XRD analysis failed to reveal any additional phases formation and decomposition except the main fcc structure. Further studies are required for the significance of the small volume of different secondary phases to the recrystallization process in the AM CrFeCoNi alloy.

Nevertheless, structural changes with heating of the AM $\mathrm{CrFeCoNi}$ alloy can be visible by utilizing the XRD line profiles. The obtained XRD line profiles were analyzed using a William-Hall (W$\mathrm{H})$ method. The $\mathrm{W}-\mathrm{H}$ plots with the full width at half maximum (FWHM) against a scattering vector for the $\mathrm{CrFeCoNi}$ powder and the $\mathrm{AM} \mathrm{CrFeCoNi}$ alloy before and after annealing at 400,700 , and $900^{\circ} \mathrm{C}$ are presented in Fig. 11a. Table 4 summarizes the obtained results by the XRD analysis as well as subgrain size and dislocation density
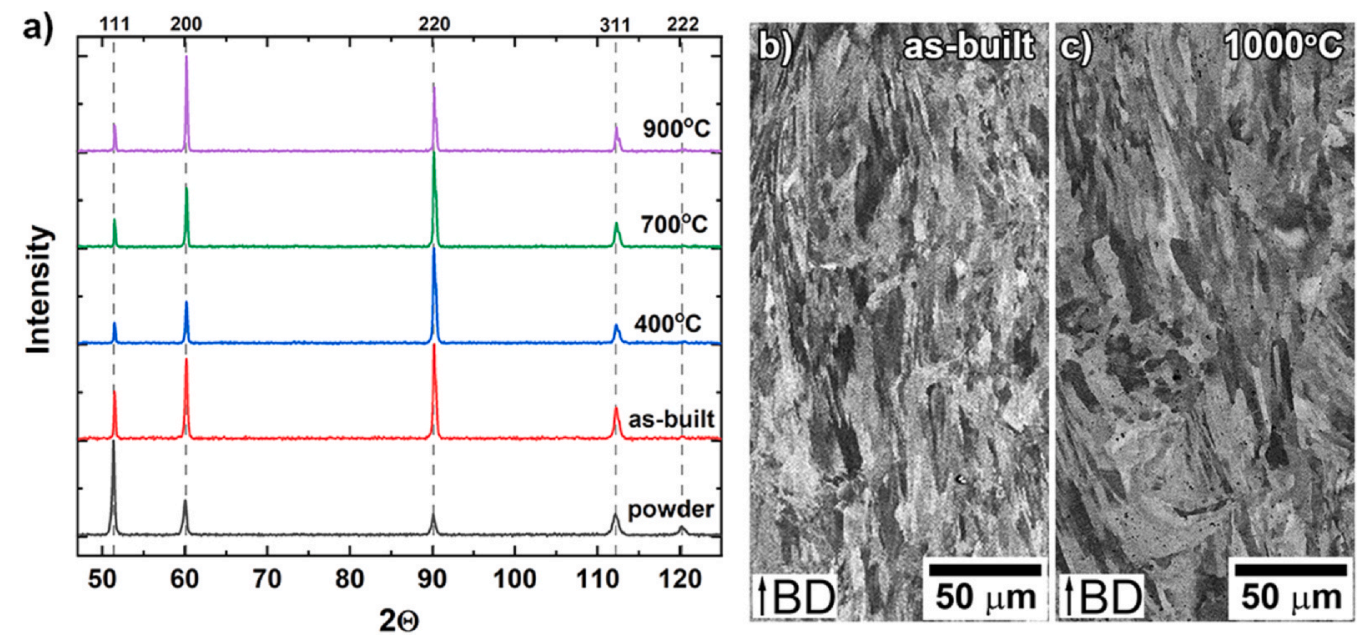

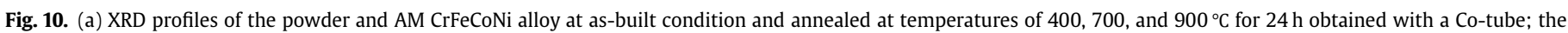
front view BSE images of (b) as-printed CrFeCoNi alloy and (c) annealed at $1000^{\circ} \mathrm{C}$ for $24 \mathrm{~h}$. 


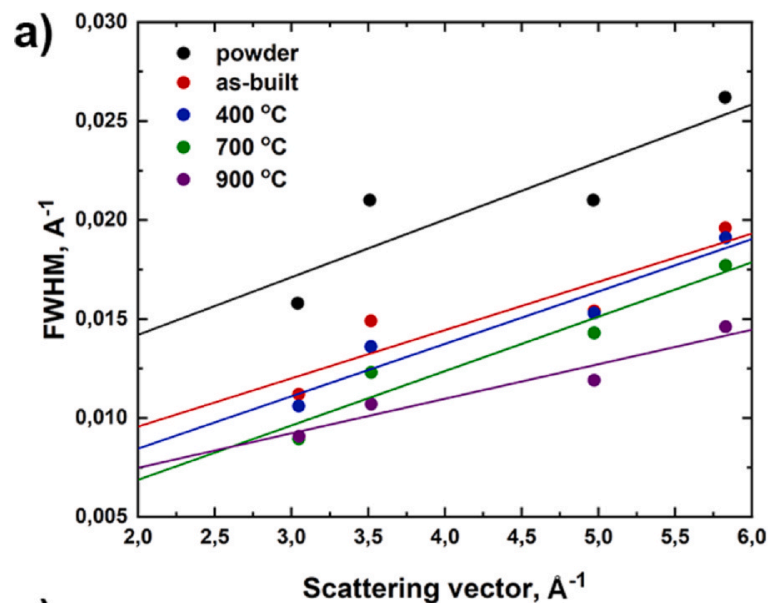

c)

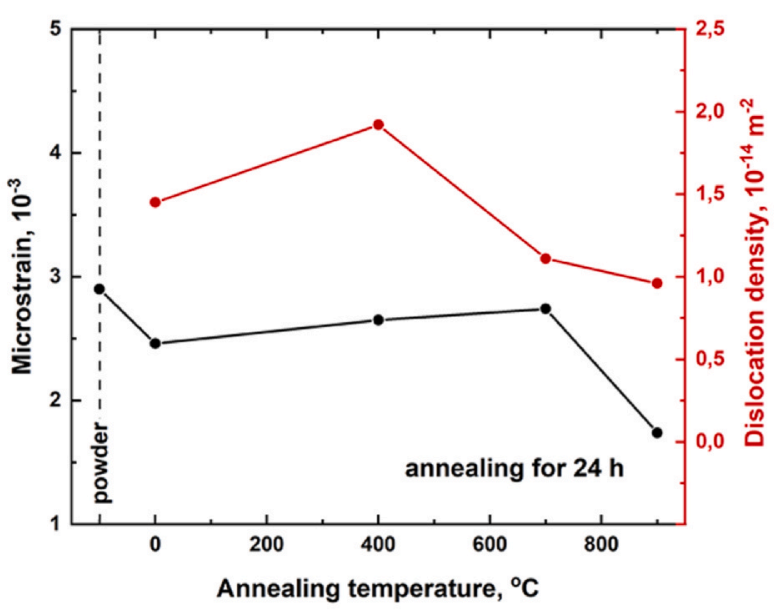

b)

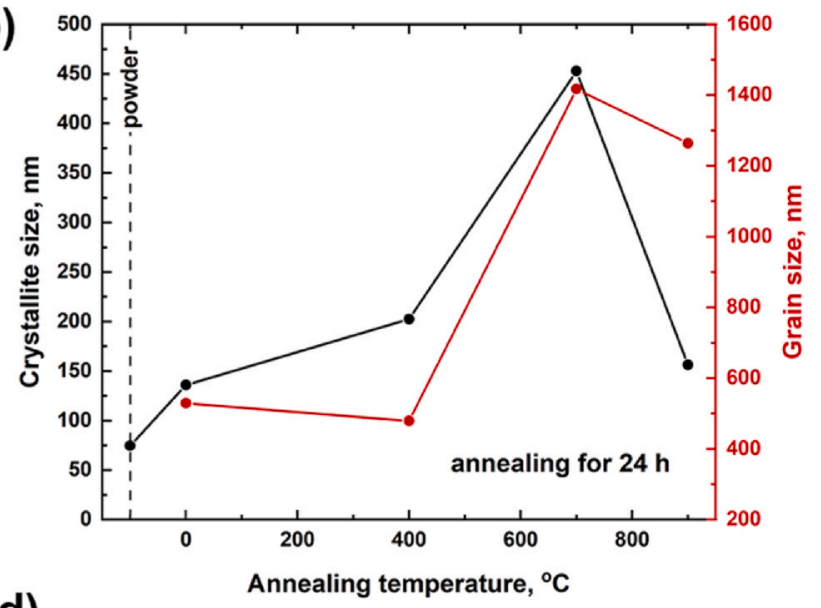

d)

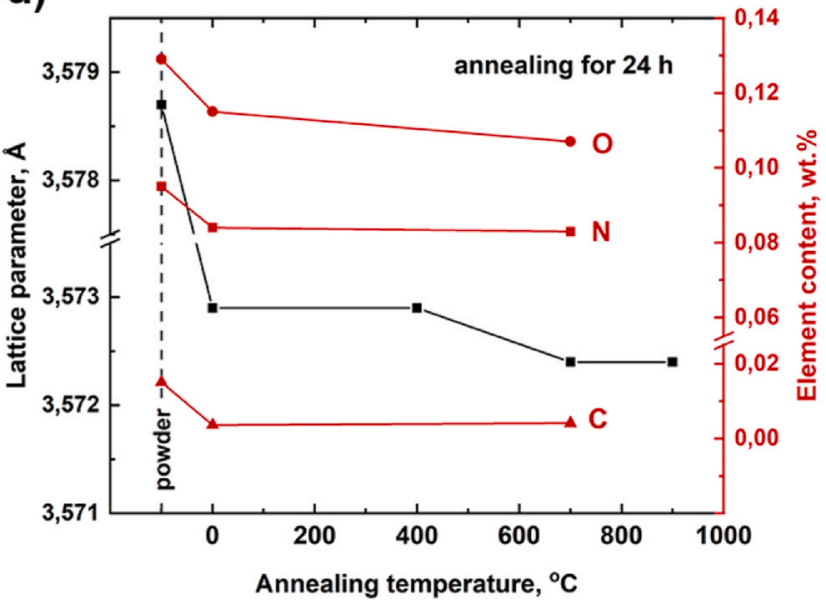

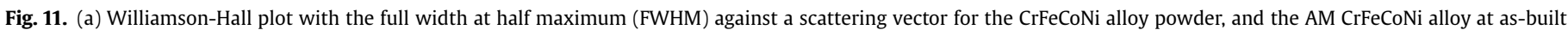

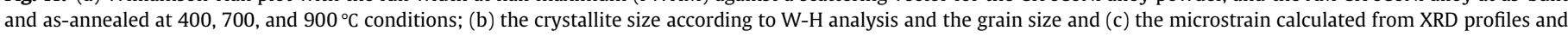

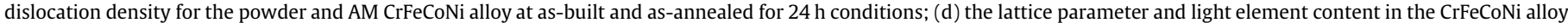
at different conditions. (For interpretation of the references to color in this figure legend, the reader is referred to the web version of this article.)

Table 4

Results of XRD profiles according to W-H method and calculations from TEM analysis.

\begin{tabular}{|c|c|c|c|c|c|}
\hline & Crystallite size, nm & Microstrain & Lattice constant, $\AA$ & Dislocation density, $\times 10^{-14} \mathrm{~m}^{-2}$ & Grain size, nm \\
\hline powder & 74.56 & 0.00290 & $3.5787 \pm 0.0010$ & - & - \\
\hline as-built & 136.05 & 0.00246 & $3.5729 \pm 0.0025$ & 1.45 & 530 \\
\hline annealed at $400^{\circ} \mathrm{C}$ & 202.44 & 0.00265 & $3.5729 \pm 0.0019$ & 1.92 & 480 \\
\hline annealed at $700^{\circ} \mathrm{C}$ & 452.75 & 0.00274 & $3.5724 \pm 0.0025$ & 1.11 & 1420 \\
\hline annealed at $900^{\circ} \mathrm{C}$ & 156.24 & 0.00174 & $3.5724 \pm 0.0032$ & 0.96 & 1260 \\
\hline
\end{tabular}

estimated by direct microstructural measurements by TEM for the CrFeCoNi alloy. XRD and TEM analyses demonstrate a consistent tendency for the structural sizes to evolve as shown in Fig. 11b. Specifically, similar structural sizes of crystallite and grain size are observed for the as-built and as-annealed samples heated at $400^{\circ} \mathrm{C}$. These increase dramatically at $400-700^{\circ} \mathrm{C}$, where the recrystallization process proceeds, and slightly decrease at $900^{\circ} \mathrm{C}$, which associates with the appearance of recrystallized small grains in the material at $900^{\circ} \mathrm{C}$. During the recrystallization, following microstructural evolution was observed: i) the cellular substructure transforms to large domains by degradation of the dislocation walls as the subgrain boundaries; and ii) some subgrain boundaries transform to the high-angle boundaries by dislocation absorption. It is worth noting that, although the general trend of the structural sizes is consistent in these two different analyses procedures, the differences often appear due to involved examination sizes, areas, and volumes where XRD oversees the global sizes and textures, while TEM analysis limits the local microstructures. It is important to note that according to the XRD and microstructure analyses, the texture in the material is observed along BD after annealing at $900-1000^{\circ} \mathrm{C}$ (Fig. 10). Only after $1200^{\circ} \mathrm{C}$ annealing, the full recrystallized structure with non-textured equiaxed grains is observed for L-PBF CrFeCoNi alloy [36]. Similar to L-PBF 3161 stainless steel [33], the L-PBF CrFeCoNi alloy demonstrates relative structural stability at intermediate temperatures of $800-1000^{\circ} \mathrm{C}$, which is associated with the features of L-PBF materials. However, additional investigations are required to better understand the grain boundary transformation during the middle- and high-temperature anneals.

Annealing at $400^{\circ} \mathrm{C}$ leads to an increase in dislocation density as shown in Fig. 11c, and it agrees with the thermal analysis revealing the beginning of the "recovery" peak. At this temperature, the dislocations move from dislocation walls in the subgrain bodies 
towards more equilibrium states, resulting in a slight increase of its density. There is an apparent decrease in the microstrain during the heat treatment at 700 and $900^{\circ} \mathrm{C}$, and the reduction of the dislocation density is observed at $700{ }^{\circ} \mathrm{C}$ (Fig. 11c). These results confirm the occurrence of a recrystallization process with microstructural relaxation followed by grain growth during heating at $700-900{ }^{\circ} \mathrm{C}$ in the AM CrFeCoNi alloy.

\subsection{Post printing heating and strengthening}

In the present work, effect of annealing temperature on microhardness of the AM CrFeCoNi alloy microhardness was demonstrated in Fig. 3a. A slight increase of microhardness is seen at temperatures of $500-600^{\circ} \mathrm{C}$. Schuh et al. showed a similar hardness behavior for an ultrafine-grained CoCrFeMnNi alloy [10], where the maximum hardness was recorded after annealing at $450{ }^{\circ} \mathrm{C}$ for one hour. They suggested there are two possible contributions to the strengthening of the alloy. First, the formation of two new secondary phases having the intermetallics character leads to promotion in strength of the ultrafine-grained $\mathrm{CoCr}$ FeMnNi alloy, while the mechanical characteristics were not determined due to a difficulty caused by their small size. Second, there is a reduction of dislocation density upon annealing. The same strengthening behavior was observed in the cold-worked $\mathrm{CoCrFeMnNi}$ alloy after one hour annealing at $600{ }^{\circ} \mathrm{C}$ which was associated with the bcc and $\sigma$ particles precipitation [9]. In the present study, increasing hardness during annealing at $500-600^{\circ} \mathrm{C}$ for $1 \mathrm{~h}$ is presented in Fig. 3b, while the annealing at $600^{\circ} \mathrm{C}$ formed the secondary phase only after the long-time heat treatment for 21 days, where the cellular structure persists during heating (Fig. 9b). Moreover, according to DSC analysis, the first endothermic peak for as-built $\mathrm{CrFeCoNi}$ alloy associated with the recovery process is observed at $500^{\circ} \mathrm{C}$, where the hardness increases by $\sim 22 \mathrm{HV}$ for the first hour of annealing. It allows the statement that strengthening after short annealing (up to one hour) is initiated due to absorption of dislocations participated in the plastic deformation to grain boundaries and annihilation of dislocations without activating the new dislocation sources. This process puts the dislocations to a more equilibrium statement which requires the additional stress effort to continue the plastic flow. It must be significant in the pre-strained materials, such as AM materials and ultrafine-grained materials.

\subsection{Secondary phase formation}

It was mentioned earlier that two precipitate types having the $\mathrm{M}_{23} \mathrm{C}_{6}$ and $\mathrm{M}_{2} \mathrm{~N}$ structures were determined in the AM CrFeCoNi alloy through TEM analysis. The $\mathrm{M}_{23} \mathrm{C}_{6}$ was observed in several studies for the CrFeCoNi systems at different temperatures [13,35], while no study has described the $\mathrm{M}_{2} \mathrm{~N}$ for a CoCrFeNi alloy. Hung et al. reveal only the main fcc structure without any additional phases for a CoCrFeNi alloy with $>99.9 \mathrm{wt} \%$ purity [12]. The purity of $>99.5 \mathrm{wt} \%$ in a CoCrFeNi alloy provides the oxides and carbides $[13,37,38]$. In the present study, the purity of the CoCrFeNi powder is $>99.7 \mathrm{wt} \%$ with the $\mathrm{N}$ impurity of $\sim 0.1 \mathrm{wt} \%$. The analysis of a pseudo-binary CoCrFeMnNi-N phase diagram shows the formation of a $\mathrm{Cr}_{2} \mathrm{~N}$ structure in the fcc matrix starting at $\sim 0.024 \mathrm{wt} \%$ at room temperature [39]. Other works also demonstrate the $\mathrm{Cr}_{2} \mathrm{~N}$ formation in CoCrFeMnNi alloy systems with at least $\sim 0.25 \mathrm{wt} \% \mathrm{~N}$ content and its strengthening effect on the material [40-43]. Due to the similar behavior of $\mathrm{CoCrFeMnNi}$ and $\mathrm{CrFeCoNi}$ alloys, the $\mathrm{N}$ content of $\sim 0.1 \mathrm{wt} \%$ is enough for the formation of an $\mathrm{M}_{2} \mathrm{~N}$ structure. Because of the high cooling rate during the printing process, such structure does not appear at the as-built condition, but, instead, it precipitates during post-printing heat treatment at $700-800{ }^{\circ} \mathrm{C}$ and stops at $\sim 900-1000^{\circ} \mathrm{C}$. In practice, the decrease of the $\mathrm{N}$ content up to $\sim 0.085 \mathrm{wt} \%$ occurs in the material at the printing process with no changes during the heat treatments. However, it can be seen that the $\mathrm{O}$ and $\mathrm{C}$ contents are also lower in the printed material compared with the powder, Fig. 11d, due to a lower surface area for the solid sample compared with powder. The decrease of the $\mathrm{CrFeCoNi}$ lattice parameter after the printing process can be associated with lower contents of light elements in material as shown in Fig. $11 \mathrm{~d}$. The further decrease of the lattice parameter after annealings at 700 and $900{ }^{\circ} \mathrm{C}$ is explained by the nitrides formation and the $\mathrm{N}$ depletion of solid solution.

The effect of secondary phase formation on the mechanical properties was discussed in earlier studies [18,23], where the $\mathrm{M}_{2} \mathrm{~N}$ precipitates were recognized as a $\sigma$-phase. It reveals dramatic effects on the ductile characteristics of the material at cryogenic temperatures and on strengthening under cycling loading. However, the formation of the $\mathrm{M}_{2} \mathrm{~N}$ precipitates observed at $700{ }^{\circ} \mathrm{C}$ annealing does not lead to any strengthening in the present study, as seen from the microhardness test results, due probably to its low content in the bulk samples.

From the present experiments, the following three comments should be noted for further studies. First, the presence of $\mathrm{N}$ as an impurity element in the powder leads to the formation of $\mathrm{M}_{2} \mathrm{~N}$ precipitates in the $\mathrm{CrFeCoNi}$ alloy at the temperature range of $700-800^{\circ} \mathrm{C}$, influencing the material properties even if the formation of the precipitates is not significant. Second, no $\sigma$-phase was observed in the AM CoCrFeNi alloy after heat treatment up to $1000^{\circ} \mathrm{C}$. As was discussed in the study [12], the solid solution can be achieved as a stable state at higher temperatures up to $1000{ }^{\circ} \mathrm{C}$ in the AM $\mathrm{CrFeCoNi}$ alloy due to the Mn absence, unlike the CoCrFeMnNi system, where the $\sigma$-phase formation initiates at temperatures of $600-900^{\circ} \mathrm{C}[9-11]$. Third, the printing process may decrease the $\mathrm{N}$ content. Possibly, the $\mathrm{N}$ content in the as-built material can be reduced by manipulating the printing process parameters, as it was demonstrated for high nitrogen steel [44].

\section{Conclusions}

The analysis of the AM CrFeCoNi alloy with post-printing heat treatment at $400-1000^{\circ} \mathrm{C}$ for $24 \mathrm{~h}$ and longer time duration was performed in the present work. According to the results, the following statements can be made:

1. The recovery process without recrystallization was observed after heating over $400^{\circ} \mathrm{C}$, and the maximum hardness was observed after one hour annealing at $500^{\circ} \mathrm{C}$. Such hardening is due to the polygonization process beginning when dislocations migrate into grain borders.

2. The recrystallization process followed by grain growth began at and above $600-700^{\circ} \mathrm{C}$, where the hardness drops continuously at $700-1000^{\circ} \mathrm{C}$, while the cellular substructure is observed after long-time heat treatment for 21 days at $600{ }^{\circ} \mathrm{C}$. The structural changes continue with increasing annealing temperature, and the strong texture in the material is observed even after annealing at $900-1000^{\circ} \mathrm{C}$ for $24 \mathrm{~h}$.

3. The presence of the nitrogen $(\sim 0.09$ wt\%) in the as-built $\mathrm{CrFeCoNi}$ sample tends to form $\mathrm{Cr}$-rich precipitates with an $\mathrm{M}_{2} \mathrm{~N}$ structure on the grain boundaries after annealing at $700-800^{\circ} \mathrm{C}$, which may affect the mechanical properties of the material, while the microhardness measurement failed to demonstrate additional hardening in the present AM alloy. The long-time heat treatment as low as $600^{\circ} \mathrm{C}$ can also lead to secondary phase formation.

4. No $\sigma$-phase formation was observed at all investigated temperatures, demonstrating the stable solid solution of the $\mathrm{CrFeCoNi}$ system at temperatures up to $\sim 1000^{\circ} \mathrm{C}$. 


\section{CRediT authorship contribution statement}

Yulia O. Kuzminova: Conceptualization, Methodology, Writing original draft, Investigation. Egor A. Kudryavtsev: Investigation. JaeKyung Han: Formal analysis. Megumi Kawasaki: Writing - review \& editing. Stanislav A. Evlashin: Resources, Writing - review \& editing.

\section{Declaration of Competing Interest}

The authors declare that they have no known competing financial interests or personal relationships that could have appeared to influence the work reported in this paper.

\section{Acknowledgments}

This study was supported in part by the National Science Foundation of the United States under Grant No. DMR-1810343 (J.K.H. and M.K.). Additionally, the work was carried out in part using the equipment of the Joint Research Center of Belgorod State National Research University "Technology and Materials» with financial support from the Ministry of Education and Higher Education of the Russian Federation within the framework of agreement No. 075-15-2021-690 (E.A.K.). Access to the Scanning Electron Microscopy facilities was granted by Advanced Imaging Core Facility of Skoltech.

\section{References}

[1] J.W. Yeh, S.K. Chen, S.J. Lin, J.Y. Gan, T.S. Chin, T.T. Shun, C.H. Tsau, S.Y. Chang, Nanostructured high-entropy alloys with multiple principal elements: novel alloy design concepts and outcomes, Adv. Eng. Mater. 6 (2004) 299-303, https:// doi.org/10.1002/adem.200300567 (+274).

[2] B. Cantor, I.T.H. Chang, P. Knight, A.J.B. Vincent, Microstructural development in equiatomic multicomponent alloys, Mater. Sci. Eng. A 375-377 (2004) 213-218, https://doi.org/10.1016/j.msea.2003.10.257

[3] D.B. Miracle, O.N. Senkov, A critical review of high entropy alloys and related concepts, Acta Mater. 122 (2017) 448-511, https://doi.org/10.1016/j.actamat. 2016.08.081

[4] M.A. Hemphill, T. Yuan, G.Y. Wang, J.W. Yeh, C.W. Tsai, A. Chuang, P.K. Liaw, Fatigue behavior of Al 0. 5 CoCrCuFeNi high entropy alloys, Acta Mater. 60 (2012) 5723-5734, https://doi.org/10.1016/j.actamat.2012.06.046

[5] B.B. Bian, N. Guo, H.J. Yang, R.P. Guo, L. Yang, Y.C. Wu, J.W. Qiao, A novel cobaltfree FeMnCrNi medium-entropy alloy with exceptional yield strength and ductility at cryogenic temperature, J. Alloy. Compd. 827 (2020) 153981, https://doi. org/10.1016/j.jallcom.2020.153981

[6] D. Liu, X. Jin, N. Guo, P.K. Liaw, J.W. Qiao, Non-equiatomic FeMnCrNiAl highentropy alloys with heterogeneous structures for strength and ductility combination, Mater. Sci. Eng.: A 818 (2021) 141386, https://doi.org/10.1016/j.msea. 2021.141386

[7] H.-P. Chou, Y.-S. Chang, S.-K. Chen, J.-W. Yeh, Microstructure, thermophysical and electrical properties in AlxCoCrFeNi $(0 \leq \mathrm{x} \leq 2)$ high-entropy alloys, Mater. Sci. Eng. B 163 (2009) 184-189, https://doi.org/10.1016/J.MSEB.2009.05.024

[8] T.S. Reddy, I.S. Wani, T. Bhattacharjee, S.R. Reddy, R. Saha, P.P. Bhattacharjee, Intermetallics Severe plastic deformation driven nanostructure and phase evolution in a $\mathrm{Al}$ 0. $5 \mathrm{CoCrFeMnNi}$ dual phase high entropy alloy, Intermetallics 91 (2017) 150-157, https://doi.org/10.1016/j.intermet.2017.09.002

[9] M.V. Klimova, D.G. Shaysultanov, S.V. Zherebtsov, N.D. Stepanov, Effect of second phase particles on mechanical properties and grain growth in a CoCrFeMnNi high entropy alloy, Mater. Sci. Eng. A 748 (2019) 228-235, https://doi.org/10. 1016/j.msea.2019.01.112

[10] B. Schuh, F. Mendez-Martin, B. Völker, E.P. George, H. Clemens, R. Pippan, A. Hohenwarter, Mechanical properties, microstructure and thermal stability of a nanocrystalline CoCrFeMnNi high-entropy alloy after severe plastic deformation, Acta Mater. 96 (2015) 258-268, https://doi.org/10.1016/J.ACTAMAT.2015.06. 025

[11] F. Otto, A. Dlouhý, K.G. Pradeep, M. Kuběnová, D. Raabe, G. Eggeler, E.P. George, Decomposition of the single-phase high-entropy alloy CrMnFeCoNi after prolonged anneals at intermediate temperatures, Acta Mater. 112 (2016) 40-52, https://doi.org/10.1016/j.actamat.2016.04.005

[12] P.T. Hung, M. Kawasaki, J.-K. Han, J.L. Lábár, J. Gubicza, Microstructure evolution in a nanocrystalline CoCrFeNi multi-principal element alloy during annealing, Mater. Charact. 171 (2021) 110807, https://doi.org/10.1016/j.matchar.2020. 110807

[13] P. Sathiyamoorthi, J. Basu, S. Kashyap, K.G. Pradeep, R. Sankar, Thermal stability and grain boundary strengthening in ultra fi ne-grained CoCrFeNi high entropy alloy composite, Mater. Des. 134 (2017) 426-433, https://doi.org/10.1016/j. matdes.2017.08.053

[14] S. Praveen, B.S. Murty, R.S. Kottada, Alloying behavior in multi-component AlCoCrCuFe and NiCoCrCuFe high entropy alloys, Mater. Sci. Eng. A 534 (2012) 83-89, https://doi.org/10.1016/j.msea.2011.11.044

[15] C. Juan, M. Tsai, C. Tsai, C. Lin, W. Wang, C. Yang, S. Chen, S. Lin, J. Yeh, Intermetallics Enhanced mechanical properties of HfMoTaTiZr and HfMoNbTaTiZr refractory high-entropy alloys, Intermetallics 62 (2015) 76-83, https://doi.org/10.1016/j.intermet.2015.03.013

[16] H. Chen, A. Kauffmann, S. Laube, I. Choi, R. Schwaiger, Y. Huang, K. Lichtenberg, F. $\mathrm{Mu}$, Contribution of lattice distortion to solid solution strengthening in a series of refractory high entropy alloys, n.d., doi: 10.1007/s11661-017-4386-1.

[17] A. Riemer, S. Leuders, M. Thöne, H.A. Richard, T. Tröster, T. Niendorf, On the fatigue crack growth behavior in 316L stainless steel manufactured by selective laser melting, Eng. Fract. Mech. 120 (2014) 15-25, https://doi.org/10.1016/j. engfracmech.2014.03.008

[18] Y. Kuzminova, D. Firsov, A. Dudin, S. Sergeev, A. Zhilyaev, A. Dyakov, A. Chupeeva, A. Alekseev, D. Martynov, I. Akhatov, S. Evlashin, The effect of the parameters of the powder bed fusion process on the microstructure and mechanical properties of CrFeCoNi medium-entropy alloys, Intermetallics 116 (2020) 106651, https:// doi.org/10.1016/j.intermet.2019.106651

[19] R. Li, P. Niu, T. Yuan, P. Cao, C. Chen, K. Zhou, Selective laser melting of an equiatomic CoCrFeMnNi high-entropy alloy: processability, non-equilibrium microstructure and mechanical property, J. Alloy. Compd. 746 (2018) 125-134, https://doi.org/10.1016/j.jallcom.2018.02.298

[20] Y. Chew, G.J. Bi, Z.G. Zhu, F.L. Ng, F. Weng, S.B. Liu, S.M.L. Nai, B.Y. Lee, Microstructure and enhanced strength of laser aided additive manufactured CoCrFeNiMn high entropy alloy, Mater. Sci. Eng. A 744 (2019) 137-144, https:// doi.org/10.1016/j.msea.2018.12.005

[21] C. Haase, F. Tang, M.B. Wilms, A. Weisheit, B. Hallstedt, Combining thermodynamic modeling and 3D printing of elemental powder blends for highthroughput investigation of high-entropy alloys - towards rapid alloy screening and design, Mater. Sci. Eng. A 688 (2017) 180-189, https://doi.org/10.1016/j. msea.2017.01.099

[22] Y. Brif, M. Thomas, I. Todd, The use of high-entropy alloys in additive manufacturing, Scr. Mater. 99 (2015) 93-96, https://doi.org/10.1016/j.scriptamat.2014. 11.037

[23] Y.O. Kuzminova, D.G. Firsov, S.A. Dagesyan, S.D. Konev, S.N. Sergeev, A.P. Zhilyaev, M. Kawasaki, I.S. Akhatov, S.A. Evlashin, Fatigue behavior of additive manufactured CrFeCoNi medium-entropy alloy, J. Alloy. Compd. 863 (2021) 158609, https://doi.org/10.1016/j.jallcom.2021.158609

[24] W. Zhao, J.-K. Han, Y.O. Kuzminova, S.A. Evlashin, A.P. Zhilyaev, A.M. Pesin, J. Jang, K.-D. Liss, M. Kawasaki, Significance of grain refinement on micro-mechanical properties and structures of additively-manufactured CoCrFeNi high-entropy alloy, Mater. Sci. Eng.: A 807 (2021) 140898, https://doi.org/10.1016/j.msea.2021. 140898

[25] D. Lin, L. Xu, Y. Han, Y. Zhang, H. Jing, Structure and mechanical properties of a FeCoCrNi high-entropy alloy fabricated via selective laser melting, Intermetallics 127 (2020) 106963, https://doi.org/10.1016/j.intermet.2020.106963

[26] J. Joseph, T. Jarvis, X. Wu, N. Stanford, P. Hodgson, D.M. Fabijanic, Comparative study of the microstructures and mechanical properties of direct laser fabricated and arc-melted AlxCoCrFeNi high entropy alloys, Mater. Sci. Eng. A 633 (2015) 184-193, https://doi.org/10.1016/j.msea.2015.02.072

[27] M. Li, J. Gazquez, A. Borisevich, R. Mishra, K.M. Flores, Evaluation of microstructure and mechanical property variations in AlxCoCrFeNi high entropy alloys produced by a high-throughput laser deposition method, Intermetallics 95 (2018) 110-118, https://doi.org/10.1016/j.intermet.2018.01.021

[28] A.M. Filimonov, O.A. Rogozin, D.G. Firsov, Y.O. Kuzminova, S.N. Sergeev, A.P. Zhilyaev, M.I. Lerner, N.E. Toropkov, A.P. Simonov, I.I. Binkov, I.V. Okulov, I.S. Akhatov, S.A. Evlashin, Hardening of additive manufactured 316L stainless steel by using bimodal powder containing nanoscale fraction, Materials 14 (2020) 115, https://doi.org/10.3390/ma14010115

[29] A. Bowman, G. Arnold, E. Storms, N. Nereson, The crystal structure of Cr23C6, Acta Crystallogr. Sect. B Struct. Crystallogr. Cryst. Chem. 28 (10) (1972) 3102-3103, https://doi.org/10.1107/S0567740872007526

[30] Y.M. Wang, T. Voisin, J.T. McKeown, J. Ye, N.P. Calta, Z. Li, Z. Zeng, Y. Zhang W. Chen, T.T. Roehling, R.T. Ott, M.K. Santala, P.J. Depond, M.J. Matthews, A.V. Hamza, T. Zhu, Additively manufactured hierarchical stainless steels with high strength and ductility, Nat. Mater. 17 (2018) 63-71, https://doi.org/10.1038/ nmat5021

[31] R. Wu, M. Zaiser, Cell structure formation in a two-dimensional density-based dislocation dynamics model, Mater. Theory 5 (2021) 3, https://doi.org/10.1186/ s41313-020-00025-X

[32] R. Wu, D. Tüzes, P.D. Ispánovity, I. Groma, T. Hochrainer, M. Zaiser, Instability of dislocation fluxes in a single slip: deterministic and stochastic models of dislocation patterning, Phys. Rev. B 98 (2018) 054110, https://doi.org/10.1103/ PhysRevB.98.054110

[33] T. Voisin, J.-B. Forien, A. Perron, S. Aubry, N. Bertin, A. Samanta, A. Baker, Y.M. Wang, New insights on cellular structures strengthening mechanisms and thermal stability of an austenitic stainless steel fabricated by laser powder-bed-fusion, Acta Mater. 203 (2021) 116476, https://doi.org/10.1016/j.actamat.2020.11.018

[34] J. Cabana, C.D. Ling, J. Oró-Solé, D. Gautier, G. Tobías, S. Adams, E. Canadell, M.R. Palacín, Antifluorite-type lithium chromium oxide nitrides: synthesis, structure, order, and electrochemical properties, Inorg. Chem. 43 (2004) 7050-7060, https://doi.org/10.1021/ic049138z 
[35] T.-T. Shun, Y.-C. Du, Age hardening of the Al0.3CoCrFeNiC0.1 high entropy alloy, J. Alloy. Compd. 478 (2009) 269-272, https://doi.org/10.1016/j.jallcom.2008.12.014

[36] Y. Kuzminova, A. Shibalova, S. Evlashin, I. Shishkovsky, P. Krakhmalev, Structural effect of low Al content in the in-situ additive manufactured $\mathrm{CrFeCoNiAlx} \mathrm{high-}$ entropy alloy, Mater. Lett. 303 (2021) 130487, https://doi.org/10.1016/j.matlet. 2021.130487

[37] S. Praveen, B.S. Murty, R.S. Kottada, Phase evolution and densification behavior of nanocrystalline multicomponent high entropy alloys during spark plasma sintering, JOM 65 (2013) 1797-1804, https://doi.org/10.1007/s11837-013-0759-0

[38] S. Praveen, J. Basu, S. Kashyap, R. Sankar, Exceptional resistance to grain growth in nanocrystalline $\mathrm{CoCrFeNi}$ high entropy alloy at high homologous temperatures, J. Alloy. Compd. 662 (2016) 361-367, https://doi.org/10.1016/j.jallcom.2015.12.020

[39] Igor Moravcik, Jan Cizek, Larissa dA. Gouvea, Jan Cupera, Ivan Guban, Ivo Dlouhy, Nitrogen interstitial alloying of $\mathrm{CoCrFeMnNi}$ high entropy alloy through reactive powder milling, Entropy 21 (4) (2019) 363, https://doi.org/10.3390/e21040363

[40] F. Xiong, R. Fu, Y. Li, D. Sang, Effects of nitrogen alloying and friction stir processing on the microstructures and mechanical properties of CoCrFeMnNi high- entropy alloys, J. Alloy. Compd. 822 (2020) 153512, https://doi.org/10.1016/j. jallcom.2019.153512

[41] D. Edgard, J. Park, B. Straumal, N. Park, Investigation on the precipitate formation and behavior in nitrogen-containing equiatomic CoCrFeMnNi highentropy alloy, Mater. Lett. 258 (2020) 126806, https://doi.org/10.1016/j. matlet.2019.126806

[42] D. Edgard, J. Park, N. Park, Strengthening of ultrafine-grained equiatomic CoCrFeMnNi high-entropy alloy by nitrogen addition, Mater. Lett. 258 (2020) 126772, https://doi.org/10.1016/j.matlet.2019.126772

[43] M. Klimova, D. Shaysultanov, A. Semenyuk, S. Zherebtsov, G. Salishchev, N. Stepanov, Effect of nitrogen on mechanical properties of CoCrFeMnNi high entropy alloy at room and cryogenic temperatures, J. Alloy. Compd. 849 (2020) 156633, https://doi.org/10.1016/j.jallcom.2020.156633

[44] A. Arabi-hashemi, X. Maeder, R. Figi, C. Schreiner, S. Griffiths, C. Leinenbach, 3D magnetic patterning in additive manufacturing via site-specific in-situ alloy modification, Appl. Mater. Today 18 (2020) 100512, https://doi.org/10.1016/j. apmt.2019.100512 